- LAtex is recognized as a cause of occupational asthma (OA) in various working environments. Latex allergy in the textile industry has been recently reported (1). We herein describe the first case of a seamstress who developed OA to latex.

A 36-year-old woman, a nonsmoker, started work as a seamstress in 1981 . She worked with cotton and gabardine. From 1991, she sewed elasticized ribbons, using a different sewing machine, for a few

days at a time at Occupational, skin irregular intervals, but almost weekly.

In 1993, she test-positive asthma in a woman sewing elastic ribbons.

developed nasal

congestion, rhinorrhea and sneezing, and runny and itchy eyes, as well as itchy skin, followed a few weeks later by chest tightness, wheezing, and cough. Symptoms occurred progressively when she worked with the elasticized ribbons, and a few days of exposure also caused nocturnal awakenings. These symptoms improved during weekends and when she was reassigned to other jobs in the same plant. When we first evaluated her in December 1997, after a week of not working with the elasticized ribbons, spirometry was normal $\left(\mathrm{FEV}_{1} / \mathrm{FVC}=2.57 / 3.191\right.$, pred 2.67/3.05 1) (2). Methacholine $\mathrm{PC}_{20}$ was $<1 \mathrm{mg} / \mathrm{ml}$ (48\% fall in $\mathrm{FEV}_{1}$ at $1 \mathrm{mg} / \mathrm{ml}$, the first concentration given) (3). Skin prick tests (SPT) with 22 common inhalants were negative; SPT with latex (Stallergènes, Paris, France, and Omega, Montreal, Canada) were positive (wheals of $5 \times 4$ and $5 \times 3 \mathrm{~mm}$, respectively) with a negative control and a histamine wheal of $5 \times 5 \mathrm{~mm}$. In January 1998, after having worked several days with the elasticized ribbons, $\mathrm{FEV}_{1} /$ FVC fell to $1.74 / 2.45$, returning to normal after salbutamol (2.78/3.38). She was treated with topical nasal and inhaled steroids (fluticasone $1000 \mu \mathrm{g} /$ day) and salbutamol as needed (higher need when at work). After withdrawal from work in February 1998, there was a marked improvement. Serial peak-flow monitoring at and off work suggested work-related asthma.

In May 1998, we performed specific inhalation challenge (SIC) in the laboratory by the method proposed by Cockcroft et al. (4).
On a control day, exposure to nebulized phosphate-buffered saline (Wright nebulizer, output=0.14 $\mathrm{ml} / \mathrm{min}$ ) for $8 \mathrm{~min}$ was not followed by any significant change in $\mathrm{FEV}_{1}$; methacholine $\mathrm{PC}_{20}$ at the end of the day was $0.7 \mathrm{mg} / \mathrm{ml}$. The next day, the subject was exposed to nebulized latex extract (Stallergènes, Paris, France) in increasing doses, starting with a dilution of $1 / 16$ for $60 \mathrm{~s}$ up to the undiluted extract for $30 \mathrm{~s}$ (the undiluted extract caused a $4 \times 4 \mathrm{~mm}$ wheal on SPT and contained $100 \mathrm{IR} / \mathrm{ml}$ of latex allergen). This exposure induced a dual asthmatic reaction with an immediate fall in $\mathrm{FEV}_{1}$ of $20.5 \%$ at $20 \mathrm{~min}$ after exposure with complete recovery at $50 \mathrm{~min}$, followed by a $16.6 \%$ fall at $5.5 \mathrm{~h}$ with complete recovery after inhaled salbutamol. The next morning, when her $\mathrm{FEV}_{1}$ was $22 \%$ lower than the previous baseline, methacholine $\mathrm{PC}_{20}$ was significantly reduced $(0.07 \mathrm{mg} / \mathrm{ml})$.

Respiratory symptoms were exacerbated for several days with nocturnal awakenings in the 3 days following SIC; she was given fluticasone $2000 \mu \mathrm{g} /$ day. By 10 days after exposure, $\mathrm{FEV}_{1}$ had returned to normal $\left(\mathrm{FEV}_{1} /\right.$ $\mathrm{FVC}=2.86 / 3.32)$, and methacholine $\mathrm{PC}_{20}$ was $0.25 \mathrm{mg} / \mathrm{ml}$.

OA to latex is reported increasingly in health-care workers $(5)$ and in other industrial environments $(6,7)$. We describe the case of latex allergy in a seamstress who developed rhinoconjunctivitis and asthma after sewing elasticized ribbons. Recently, latex allergy was demonstrated in 2/10 workers in an elasticized ribbonmanufacturing plant, one of them experiencing work-related asthma confirmed by SIC (1). These workers were sensitized by handling powdered natural rubber, like health-care workers who wore powdered natural rubber gloves, where the latex allergen is adsorbed to the air-suspended powder. Our subject was exposed to rubber in a form that is not usually sensitizing by inhalation; however, sewing the elasticized ribbons induced a fine white dust of cloth and latex that could be inhaled, explaining the route of sensitization.
This case illustrates that one should be mindful of the possibility of latex allergy in different occupational settings.

Acknowledgments We thank Lori Schubert for reviewing the manuscript, and the technicians for their collaboration.

*Department of Chest Medicine, Sacré-Coeur Hospital, 5400 West Gouin Blvd., Montréal, Québec, Canada H4J 1C5, Tel. (514) 338 2796; Fax: (514) 338 3123; E-mail: cartiera@ere.umontreal.ca

Accepted for publication 30 November 1998 Copyright (C) Munksgaard 1999 ISSN 0105-4538

References

1. Pisati G, Baruffini A, Bernabeo F, Falagiani P. Environmental and clinical study of latex allergy in a textile factory. I Allergy Clin Immunol 1998;101:327-329.

2. Knudson R, Lebowitz M, Holberg C, Burrows B. Changes in the normal maximal expiratory flow-volume curve with growth and aging. Am Rev Respir Dis 1983;127:725-734.

3. Cockcroft D, Killian D, Mellon J, Hargreave F. Bronchial reactivity to inhaled histamine: a method and clinical survey. Clin Allergy 1977;7:235-243.

4. Cockcroft D, Ruffin R, Frith $P$, et al. Determinants of allergen-induced asthma: dose of allergen, circulating IgE antibody concentration, and bronchial responsiveness to inhaled histamine. Am Rev Respir Dis 1979;120:1053-1058.

5. Vandenplas O, Delwiche JP, Evrard G, et al. Prevalence of occupational asthma due to latex among hospital personnel. Am I Respir Crit Care Med 1995;151:54-6o.

6. Tarlo S, Wong L, Roos J, Booth N. Occupational asthma caused by latex in a surgical glove manufacturing plant. I Allergy Clin Immunol 1990;85:626-631.

7. Orfan N, Reed R, Dykewicz M, Ganz M, Kolski G. Occupational asthma in a latex doll manufacturing plant. J Allergy Clin Immunol 1994;94:826-830.

\section{Specific immunotherapy for occupational latex allergy}

C. Pereira*, P. Rico, M. Lourenço,

M. Lombardero, J. Pinto-Mendes, C. Chieira 
Key words: hypersensitivity; immunotherapy; latex; occupational disease.

- LATEX allergy in health workers is an increasingly worrisome type of occupational disease. Its prevalence ranges from $12 \%$ to $18 \%$, with different symptoms and clinical manifestations, and the disorder represents a serious social and occupational problem for individuals with severe symptoms $(1,2)$. An association between latex allergy and hypersensitivity to certain fruits and nuts is also frequently seen (latex-fruit syndrome) (3).

We present a 31-year-old white female patient who had been employed as a radiology technician since the age of 24 years. She reported palpebral

edema and burning A case of latex allergy and itching of the effectively treated by nose and eyes of specific immunotherabout 2 years' apy with aqueous duration. The extracts.

symptoms ap-

peared while she

was at work, when she spent time in areas where latex gloves had been used. Her symptoms became progressively more severe, with the appearance of intense, sudden-onset urticaria approximately $5 \mathrm{~min}$ after exposure in areas of skin that had been in contact with latex gloves. At the same time, she developed severe nasal congestion and obstruction, with prolonged bouts of sneezing. In March 1997, she developed two acute anaphylaxis crises after eating chestnuts and figs, and hospitalization was required for both.

Personal antecedents of note included intestinal surgery in 1992 and cesarean delivery in November 1996. No problems with anesthesia or allergic reactions were noted on either occasion. No family history of atopy was found.

In April 1997, she was referred to the immuno-allergy department for clinical and laboratory studies.

A skin prick test (SPT) with allergenic extracts was performed with a standard battery of aeroallergens (ALK/Abelló, Madrid,
Spain), food allergens (Leti, Barcelona, Spain), and latex-allergen extract from two suppliers (ALK-Abelló and Stallergènes).

Sensitization to latex was demonstrated by SPT and RAST, as was skin reactivity to chestnut, kiwi, and banana.

We administered specific immunotherapy (SIT) with latex allergens in the immunoallergy department while the patient was in the hospital on short-term admission, under close surveillance by specialists. The Guidelines of the Position Paper of the European Academy of Allergology and Clinical Immunology (EAACI) were followed (4), exposure to latex was minimal, and staff members of our service were in constant contact with the emergency service during treatment. The patient gave her informed written consent to receive treatment, which was approved by our hospital's ethics committee.

Latex extract was prepared from an ammonia latex particle suspension by neutralization, semipurification, and concentration, essentially as previously described by Morales et al. (5). Treatment extract (ALK-Abelló, Madrid, Spain) was dosed in $10 \%$ glycerol, $0.9 \% \mathrm{NaCl}$ buffer at 10 -fold dilutions, the highest potency being $100 \mu \mathrm{g} /$ $\mathrm{ml}$. The vials were labeled $\mathrm{A}^{\prime}(0.01 \mu \mathrm{g} / \mathrm{ml})$, A $(0.1 \mu \mathrm{g} / \mathrm{ml}), \mathrm{B}(1 \mu \mathrm{g} / \mathrm{ml}), \mathrm{C}(10 \mu \mathrm{g} / \mathrm{ml})$, and D $(100 \mu \mathrm{g} / \mathrm{ml})$.

After the extract was given, the patient remained under observation in the hospital for $4 \mathrm{~h}$ (a period much longer than that recommended for SIT with other allergens), and her general condition and vital signs were monitored closely. Local and systemic adverse reactions were classified according to the

EAACI guidelines (4).

During the build-up phase, a single weekly dose was given initially, starting with vial A $(0.3,0.5$, and $0.8 \mathrm{cc})$ and followed by vial A in 6 weeks (0.1, 0.2, 0.4, 0.5, 0.7, and $0.8 \mathrm{cc}$ ). Starting with vial B $(1 \mu \mathrm{g} / \mathrm{ml})$, the schedule was accelerated at the patient's request. She remained hospitalized during this part of the schedule, and the interval between the two injections on any given day was $3 \mathrm{~h}$. On day 4 at this concentration after a previous injection of $0.40 \mu \mathrm{g}$ protein $(0.40 \mathrm{cc})$, a second injection of $0.50 \mathrm{cc}$ was given. This led, after $40 \mathrm{~min}$, to a systemic reaction consisting of urticaria and cutaneous erythema, eye congestion,

dysphonia, hoarseness, and dyspnea, with blood pressure of 100-160 mmHg. These symptoms remitted after $10 \mathrm{~min}$ in response to treatment with epinephrine,

methylprednisolone, and clemastine. From day 65 , we initially reduced the once-daily dosis to $0.35 \mathrm{cc}$ for 2 more days and increased it again to $0.40 \mathrm{cc}$ (0.4 $\mu \mathrm{g}$ protein) on days 70 and 72 . The $0.4-\mathrm{ml}$ dose, on day 72 , was the maximum tolerated dose, and was thus used as the maintenance dosis MD. This dose was reached after 20 injections with a cumulative dose of $3.99 \mu \mathrm{g}$ protein.

Once the maximum tolerated dose was reached ( $0.40 \mu \mathrm{g}$ protein), it was given weekly for 5 weeks. The rest of the maintenance dose was given at 2-week intervals. At the time of writing, the patient had been receiving treatment for 5 months, of which time 10 weeks corresponds to the maintenance period. During this period, she received 8 s.c. injections of extract, equivalent to a cumulative dose of $3.2 \mu \mathrm{g}$ protein. The total cumulative dose of protein received since the start of SIT was $7.19 \mu \mathrm{g}$ in a total of 28 injections.

We emphasize this patient's excellent adaptation to treatment, and full compliance with the schedule of allergen extract administration and tests.

Immunotherapy with this latex extract produced no alterations in the main lymphocyte subpopulations, serum levels of immunoglobulins, and other laboratory values.

Skin tests for latex and food allergens were repeated several times during desensitization, before SIT was started and before the dose of allergen was increased. With regard to the cutaneous response to latex, the mean diameter of the papule decreased steadily with both of the commercial extracts tested: from 110 to $17 \mathrm{~mm}$ with the ALK-Abelló product, and from 45 to $18 \mathrm{~mm}$ with the Stallergènes 
extract. There were parallel decreases in the reactions to food allergens derived from banana, kiwi, and chestnut.

Absolute values of IgE to latex showed no significant alterations except at the end of the study, when an increase of approximately 4-6 URAST/ml was seen. However, IgE specific for chestnut clearly decreased during treatment from 0.72 to 0.30 $\mathrm{kU} / 1)$. The behavior of IgG class specific for latex was similar to that of specific IgE. We did not detect latex-specific $\operatorname{IgG}_{4}$ during the study; however, this immunoglobulin apparently began to appear at the end of the study.

Clinical symptoms improved steadily, with an evident reduction in nasal obstruction and eye manifestations. This was corroborated by the patient, who reported improvement even in areas of the hospital that produced significant exposure to latex gloves, which she had previously been unable to tolerate.

Acquisition of tolerance to the environment in her workplace was gradual during SIT, but was more pronounced once the maintenance period was started upon her discharge from the hospital and return to work. Because of the occupational nature of the allergy, the best provocation test for the allergen was constant exposure to latex in the workplace. However, we also used specific, controlled provocation tests. The patient entered a $1-\mathrm{m}^{3}$ airtight cabin and handled four pairs of latex gloves for $15 \mathrm{~min}$; her clinical symptoms were then evaluated during the $6 \mathrm{~h}$ following this exposure to the allergen. Clinical examination after the provocation test showed that she had no cutaneous, eye, nasal, or bronchial symptoms during the following $6 \mathrm{~h}$.

In terms of local reactions, tolerance of SIT was excellent, with no delayed local reactions and only one episode of immediate local reaction during the maintenance phase (erythema with papules measuring $60 \mathrm{~mm}$ in mean diameter). This reaction did not require treatment or a change in the desensitization schedule.

We believe that the allergenic extract is safe, at least at concentrations up to $0.4 \mu \mathrm{g}$ latex protein. Tolerance was excellent, and, like other authors who used accelerated schedules (6), we established the MD on the basis of the appearance of a systemic reaction. We felt this to be the most prudent approach, in contrast to other studies in which the appearance of a systemic reaction led only to a change in the dose schedule $(7,8)$. Use of a conventional schedule would probably have allowed us to reach a higher $\mathrm{MD}$, a possibility that deserves further study.

We consider SIT with latex to be highly effective, and found the allergenic extract used to be safe and well tolerated.

*Imuno-Alergologia, Hospitais da Universidade de Coimbra, 3000 Coimbra, Portugal

Accepted for publication 15 December 1998 Copyright (C) Munksgaard 1999

ISSN 0105-4538

\section{References}

1. Liss GM, Sussman GL, Deal K, et al. Latex allergy: epidemiological study of 1351 hospital workers. Occup Environ Med 1997;54:335-442.

2. Leynadier F. Occupational latex allergy [Letter]. I Allergy Clin Immunol 1996;98:716-717.

3. Brehler R, Theissen $\mathrm{U}$, Mohr C, Luger $\mathrm{T}$. Latex-fruit syndrome: frequency of crossreacting IgE antibodies. Allergy

1997;52:404-410.

4. Malling H-J, Weeke B. Position paper. Immunotherapy. Allergy 1993;48 Suppl 14:9-35.

5. Morales C, Basomba A, Carreira J, Sastre A. Anaphylaxis produced by rubber glove contact. Case reports and immunological identification of the antigens involved. Clin Exp Allergy 1989;19:425-430.

6. Nelson BL, Dupont LA, Reid MJ. Prospective survey of local and systemic reactions to immunotherapy with pollen extracts. Ann Allergy 1986;56:331-334.

7. Østerballe O. Immunotherapy in hay fever with two major allergens of 19, 25 and partially purified extract of timothy grass pollen. A controlled double blind study. In vivo variables, season I. Allergy 1980;35:473-489.

8. Olaguibel JM, Tabar AI, García Figueroa BE, Cortés C. Immunotherapy with standardized extract of Dermatophagoides pteronyssinus in bronchial asthma: a dose-titration study. Allergy 1997;52:168-178.

\section{Allergen-induced matrix metalloproteinase-9 in nasal lavage fluid}

\author{
A.W. van Toorenenbergen*, R. Gerth van \\ Wijk, A.M. Vermeulen
}

Key words: allergic rhinitis; eosinophil cationic protein (ECP); metalloproteinase; MMP-9.

- IN an individual with allergic rhinitis, exposure to allergens leads to rapid release of mast-cell-derived mediators. In about half of the subjects, this immediate nasal response is followed $3-12 \mathrm{~h}$ later by a latephase response (1). This secondary response is induced by inflammatory cells, which have accumulated in response to mast-cellderived chemotactic factors (1). Bronchoalveolar eosinophilia is a hallmark of late-phase IgE-mediated reactions (2).

Okada et al. (3) recently showed that matrix metalloproteinase-9 (MMP-9) is required for migration of eosinophils through basement membrane components in vitro. Indeed, elevated levels of MMP-9 were recently found in the bronchoalveolar lavage fluid of asthmatics (4).

In a previous

study (5), we

measured albumin,

eosinophil cationic

protein (ECP), and

other mediators in

nasal lavage

samples obtained

Nasal provocation with allergen induces a parallel release of ECP and matrix metalloproteinase-9 during the late-phase inflammatory response.

before and up to

$10 \mathrm{~h}$ after nasal

allergen provocation. In the present study, we sought for MMP-9 in five series of these nasal lavage samples. Our results show a parallel release of ECP and MMP-9 after nasal provocation with allergen. Allergic rhinitis of the five patients involved in this study was confirmed by positive skin tests to grass pollen and/or house-dust-mite extract. Informed consent was obtained from all patients, and 